\title{
The Deaf Mentor Program: Benefits to Families
}

\author{
Beth Hamilton, M. Diane M. Clark \\ Lamar University, Beaumont, TX, USA \\ Email: mclark22@lamar.edu
}

How to cite this paper: Hamilton, B., \& Clark, M. D. M. (2020). The Deaf Mentor Program: Benefits to Families. Psychology, 11, 713-736.

https://doi.org/10.4236/psych.2020.115049

Received: April 8, 2020

Accepted: May 25, 2020

Published: May 28, 2020

Copyright (C) 2020 by author(s) and Scientific Research Publishing Inc. This work is licensed under the Creative Commons Attribution International License (CC BY 4.0).

http://creativecommons.org/licenses/by/4.0/ (c) (i) Open Access

\begin{abstract}
Most Deaf children are born to hearing parents, who have little to no experience with Deaf people, their language, or their culture. These parents struggle with how to raise a Deaf infant who responds primarily to visual rather than auditory information. A program called Deaf Mentors was developed to connect these hearing families with a Deaf adult who is trained in how to effectively help parents learn visual strategies and if desired sign language to facilitate early language acquisition. This study, using a grounded theory methodology, investigated the perceptions of hearing families who had a Deaf Mentor. Results found that these Deaf Mentors helped families create a context that provided the Keys to a High Quality of Life for Deaf Children. Importantly, the program provided a new perspective that allowed families to understand that their Deaf child was different but not broken.
\end{abstract}

\section{Keywords}

Deaf Mentor, Deaf Crit, Early Intervention, Medical \& Socio-Cultural Perspectives, Grounded Theory

\section{Introduction}

When an infant is identified as Deaf or hard of hearing, professionals often recommend hearing technologies, such as digital hearing aids and cochlear implants, so that they can acquire spoken language. However, limited auditory access impacts language acquisition for most prelingually Deaf children as these technologies do not provide complete access immediately after birth and during the critical period for language acquisition. Therefore, Deaf children may not be able to acquire a spoken language via the acoustic channel (Lieberman, Hatrak, \& Mayberry, 2011; Klaudia, 2013; Mayberry, 2002; Mayberry \& Lock, 2003). Moreover, parents need to be aware that not all Deaf children have the ability to develop spoken language in the same way as their hearing peers, even with these newer hearing technologies (Mitchiner, 2015). Therefore, providing sign lan- 
guage at the point of being identified as Deaf, permits a Deaf child the opportunity to develop age-appropriate language. This access to a visual language is important because contrary to beliefs held by the medical and audiological communities (Nussbaun et al., 2004), using a sign language does not require that spoken language be excluded; the use of sign language and the development of spoken/written language can occur in parallel (Davidson, Lillo-Martin, \& Pichler, 2014; Hassanzadeh, 2012; Humphries, et al., 2016; Klaudia, 2013; Rinaldi \& Caselli, 2014; Swanwick \& Watson, 2005).

Humphries et al., (2012) noted that using ASL does not prevent Deaf children from learning, or being able to understand, spoken language. It actually benefits these children to have ASL as their L1, as it provides a foundation and support for later spoken language development (Hassanzadeh, 2012; Rinaldi \& Caselli, 2014). Additionally, ASL establishes the neurological structures for language processing in the same way as a spoken language (Pénicaud, et al, 2013). Importantly, the use of sign language from an early age does not discourage interest in learning speech (Swanwick \& Watson, 2005) and seems to contribute to spoken language development (Humphries et al., 2012; Petitto \& Holowka, 2002; Vasquez, Pease-Alvarez, \& Shannon, 1994).

Early intervention services, including audiologists, social workers, and medical professionals, are usually involved with universal newborn hearing screening. This screening most frequently happens prior to the family leaving the hospital after the infant's birth (Benedict, 2013). Interestingly, professional Deaf people who could help parents learn how to raise their Deaf child, typically are not involved with this process. Therefore, hearing families often are presented with information that only focuses on teaching their children spoken language; additionally, some parents are actively told not to use sign language in their child's life (Mauldin, 2016). As a result, Deaf children face not only language deprivation or language delay, but also cognitive and social delays (Humphries et al., 2012; Kushalnagar, et al, 2010; Marschark, 2001). These early intervention and medical professionals often lack any kind of training or specific understanding of how to work with Deaf children, other than seeing them as needing to be "fixed" (Butler, Skelton, \& Valentine, 2001). Therefore, this exclusion of Deaf individuals from the early intervention process limits hearing parents' perceptions regarding their Deaf infant's potential as it relies on the standard epistemology typically used by medical professionals.

When hearing individuals look at a Deaf person, the typical focus is that of this standard epistemology, which views Deaf people as defective and needing to be fixed. In contrast from a Deaf epistemology, being Deaf itself is a cultural and linguistic difference (Holcomb, 2013) and does not necessarily lead to a disability if appropriate access to communication and language is provided. Rather, the disability is within the culture, which views a Deaf child as having a deficit (Bauman \& Murray, 2013). In contrast, the concept of Deaf Gain reframes (Lakoff, 2004) a Deaf individual as one who contributes diversity to society, in other words, the glass is half full, rather than half empty (Bauman \& Murray, 2013). 
Using this frame of Deaf Gain, one finds that Deaf children who have early access to a visual language obtain typical linguistic milestones (Mayberry \& Lock, 2003; Simms, Baker \& Clark, 2013) and develop similar brain structures (Mayberry, et al., 2011) and functions (Pénicaud, et al, 2013) as do children exposed to a spoken language. This focus on Deaf Gain provides a counter narrative about being Deaf which benefits all of society. This perspective is commonly known as a "Deaf way of knowing" (Hauser, O’Hearn, McKee, \& Steider, 2010; Holcomb, 2010; Lane, 2005).

The Deaf community (Hauser, 2013; Listman, Rogers, \& Hauser, 2011) can be seen as having vital cultural capital to share about raising Deaf children. This notion of Deaf cultural capital builds on the work of Yosso regarding cultural capital, defined as non-financial resources that help individuals improve their social status. This capital comes in various forms, including human capital (i.e., the "what' you know), social capital (i.e., "who" you know), and cultural capital (i.e., "how" you know; Yosso, 2005). Listman, Roger, and Hauser (2011) expanded Yosso's (2005) ideas about cultural capital and applied them to Deaf cultural capital, which here is called community cultural capital (Deaf CCC), but sometimes is referred to as community cultural wealth.

Deaf CCC includes six specific components, but here we combine several and use only four. Familial capital is not included here as hearing parents typically struggle to share their own cultural wealth with their Deaf child; rather this type of capital will be referred to as community capital to include linguistic and Deaf familial capital. Next, aspirational capital is derived from stories about Deaf people overcoming adversity as well as seeing Deaf role models, such as teachers, scientists, or medical doctors. Then, navigational capital includes strategies passed down by the community to allow Deaf individuals to survive in a hearing world (Holcomb, 2013). The final capital is resistance capital where Deaf children learn to develop a positive identity, focus on their own strengths, and avoid the negative view embedded within the system level. Deaf CCC shares the lessons learned within Deaf culture on how to raise a Deaf child as well as how to navigate through a hearing world. Unfortunately, most hearing parents are unaware of Deaf CCC and may never have met a Deaf person before (Benedict, 2013).

Given that hearing people tend to be unaware of successful Deaf individuals, when they meet a hearing family with a Deaf child, their standard response is often, “Oh, I am so sorry that your child is Deaf” (Benedict \& Stecker, 2011). However, when a Deaf person meets a hearing family with a Deaf child, their response is, "That is great. What are you doing to promote their communication, language, and learning acquisition?" These statements show the opposing perspectives and attitudes from two different communities.

This different perspective is part of human nature, as most of us want to stay with what is known, because it is familiar. Therefore, a hearing family is likely to want their child to fit into hearing culture and most likely is completely unaware of Deaf culture (Benedict, 2013). Therefore, for the hearing family who has a 
Deaf child, they usually want to "fix the child's hearing." On the other hand, Deaf people's perspective about being Deaf is positive, because they understand the history, heritage, language, arts, traditions, and visual ways of learning which make up Deaf culture (Holcomb, 2013; Leigh, Andrews, \& Harris, 2018; Solomon, 2012). These two views can be interwoven if hearing parents are provided complete access to information about all available language options. For many Deaf children, fitting into the hearing world is neither easy nor completely effective, leading them to pass for hearing (Harmon, 2013) as they struggle to fit into the culture of their parents.

In contrast to this focus on auditory access to information, Deaf Mentors can teach hearing parents how to help a visually focused infant access information. Deaf Mentors bring knowledge that has been developed by a linguistic community that relies on visual access to language, communication, and culture (Holcomb, 2013). Within this visual culture, the capitalized "Deaf" is used to refer to Deaf people who share a natural language-American Sign Language (ASL) and a complex culture and history, created and actively transmitted across generations visually (Padden \& Humphries, 1988). Additionally, here Deaf will be used to refer to all Deaf and Hard of Hearing people as an inclusive term as defined by the Deafhood Foundation (deafhood.org). Here the focus is on Deaf Mentors who can provide this knowledge to hearing families who are raising a Deaf child. This Deaf-centric knowledge is frequently not conveyed by hearing professionals when parents initially are told that their child is Deaf, which can lead them to see their infant as "broken" and needing to be "fixed". In contrast, these Deaf Mentors help hearing families gain Deaf CCC. Next is a discussion of the training and benefits of having a Deaf Mentor.

Benefits of Deaf Mentors. Deaf Mentors have been available for decades (Jacobi, 1991). Each one attends the Deaf Mentor Basic Training Workshop for three days to learn how to deliver the National Ski Hi Deaf Mentor curriculum to track and improve language for young Deaf children. They focus is on providing hearing families early ASL knowledge as well as strategies to support the Deaf child's English. In this way, Deaf children become ASL/English bilinguals and are able to be academically successful and communicate with both Deaf and hearing people (Watkins, Pittman, \& Walden, 1998). In addition, Deaf Mentors share Deaf culture and connect the family to the local Deaf community. For example, Rhodes and DuBois (2008) discuss the potential impacts of having a Deaf Mentor, which provides community capital, aspirational capital, and navigational capital. They describe how Deaf Mentors forge relationships that include mutuality, trust, and empathy, thereby providing aspirational capital. Mentors learn about the child and their family's interpersonal history, social competencies, developmental stages, and community context (Rhodes, Grossman, \& Resch, 2000) and they then understand the needs of the family. This knowledge allows them to teach parents how to contribute to the child's social-emotional development, identity development, and cognitive development (Rhodes, Spencer, Keller, Liang, \& Noam, 2006) by providing navigational and 
community capitals. This transfer of capital leads to more positive outcomes in the child's life. Additionally, it can remove worries and anxieties that might be expressed by the parents or family members of a Deaf child, as they work with a Deaf adult who is successful and productive, giving them the aspirational capital needed to guide their child. The National Center for Hearing Assessment and Management at Utah State University's (NCHAM; infanthearing.org, 2020) website has information on how to obtain a Deaf Mentor and helps direct parents to local resources to obtain one.

Once a child is identified as Deaf, a Deaf professional, such as a Deaf Mentor, can bring knowledge, experiences, and beneficial solutions to the early intervention process. Currently seven to ten states have Deaf Mentor Programs that utilize the curriculum developed by Sensory Kids Impaired Home Intervention (SKI-HI), which is pronounced sky-high (Hamilton, 2013). Including a Deaf Mentor on the team who initially meets the parents with the information that the child is Deaf, provides a role model of what their own child can accomplish; thereby giving psychological relief to parents who often suffer from the anxiety of not knowing what to expect with their Deaf child. These shocked hearing parents are concerned about what strategies to use for communication and language acquisition (Benedict et al., 2009). These strategies can include Deaf Mentors who can teach hearing families how to get their Deaf child's attention, regulate eye gaze (Clark \& Daggett, 2015), and develop joint attention strategies (Lieberman et al., 2011; Lieberman, Hatrack \& Mayberry, 2014) using indigenous strategies developed by the Deaf community (Holcomb, 2013; Humphries, 2004).

Prior Research on Deaf Mentors. Only two published studies have evaluated the impact of Deaf Mentors. Watkins, Pittman, and Walden's (1998) longitudinal study investigated children who had Deaf Mentors in Utah as well as children without Deaf Mentors in Tennessee. The Utah families were learning and using ASL as well as CASE (conceptually accurate signed English). In the Tennessee sample, the children were in traditional parent infant programs, where half of the children used spoken language and the other half used total communication and Signed Exact English (SEE, a concept that borrows the signs from ASL and applies it using English grammar; Goldin-Meadow \& Mayberry, 2001). In this study, the diagnosticians were carefully trained to administer and score assessments focused on four linguistic areas; a Grammatical Analysis of Elicited Language, a measure called the Pre-Sentence Level, the Patterned Elicitation Syntax Test SKI-HI Language Developmental Scale, and the Communication Data Sheet (Watkins, et al., 1998). At the end of the three-year period, the Deaf children who had Deaf Mentors showed greater progress in social and cognitive areas as well as demonstrated more language in comparison to those that did not have a Deaf Mentor (Watkins et al., 1998).

In the second Deaf Mentor study, Rogers and Young (2011) looked at families using Deaf Mentors in the United Kingdom. They found that Deaf children with Deaf Mentors gained self-esteem and their families gained confidence that their 
Deaf child could succeed in life. Also, the families gained an understanding of how to provide support for their Deaf child's success in life because they had both the Deaf Mentors' knowledge and visual tools. Both Watkins et al. (1998) and Rogers and Young (2011) demonstrate that having a Deaf Mentor allows families to understand and set high expectations for their Deaf child, as well as to increase their communication and language development.

Deaf Mentors assist families in understanding "how" to raise a Deaf infant as a psychologically and socially healthy child (Singleton \& Tittle, 2000). The path to optimum development can be through ASL and spoken English bimodal bilingualism, ASL and written English bilingualism (Grosjean, 2008) or spoken language, depending on what language the parents prefer for their child. Having a Deaf Mentor can provide a consistent language model (Hamilton, 2017) and provide community capital through this modeling of ASL to parents for the ease of communication with their Deaf child.

Broader Benefits of Deaf Mentors. However, the role of these Deaf Mentors is not only with Deaf children and their families. Professionals, such as audiologists, speech therapists, as well as organizations who provide help to families (e.g., American Society for Deaf Children) can benefit from the indigenous knowledge of Deaf Mentors (Corina \& Singleton, 2009). Deaf Mentors provide these professionals with information to help understand Deaf culture, the benefits of sign language, and how language acquisition differs between Deaf children and hearing children (Hintermair, 2000). These Deaf Mentors provide access to Deaf CCC in ways that can be shared with hearing families.

Deaf Mentors are continuously trained, so as to have the most up-to-date information. The Deaf Mentor Program (Pittman, SKI-HI, \& HOPE, 2001) is an effective method for addressing questions that families and professionals might have, and it builds a bridge between the Deaf and hearing communities (Hamilton, 2013) by sharing navigational capital. Therefore, the impact of involving Deaf Mentors occurs at both the individual as well as the societal/professional level.

Deaf Mentors bring knowledge of the challenges a Deaf child will experience from their own personal and professional experiences. They then share this information with hearing families and assist them in learning how to navigate the barriers that their child most likely will encounter (Cawthon, Johnson, Garberolgio \& Schoffstall, 2016). Everyone's desire is for the Deaf infant to have a strong language foundation; the language debate centers around the best practices to achieve this end result.

Knowledge of how to Obtain a Deaf Mentor. Hamilton (2013) found that many families were not familiar with the Deaf Mentor Program, with $50 \%$ of those families surveyed having no knowledge of it. Almost $60 \%$ of the families expressed an interest in receiving services from a Deaf Mentor, if it was available to them (Hamilton, 2013). To follow up on this lack of knowledge, investigated 55 families with a Deaf child from this group, 36 families asked for Deaf Mentors. An additional 19 families were automatically offered Deaf Mentors. Impor- 
tantly, these families who had automatically been provided with a Deaf Mentor were unaware that the services existed. The majority of the parents who did not participate in the Deaf Mentor program stated that they were unaware of the program (Minnesota Department of Health Newborn and Child Follow-Up Unit, 2015). Clearly, the Deaf Mentor Program is not widely known across the US; therefore, parents do not know that they could ask for this type of service.

The Current Study. These earlier studies show how providing Deaf CCC can improve the lives of hearing families with Deaf children. The program normalizes having a Deaf child and allows the family to feel confident in nurturing their child. These studies share the intuitions of Deaf adults and prevent additional Deaf children from growing up with severe cognitive and linguistic delays (Johnson, Liddell, \& Erting, 1989). However, these programs are not integrated into early intervention programs in many areas, leaving hearing parents without the knowledge that the Deaf community can provide. The rationale for investigating hearing parents' perceptions of using a Deaf Mentor was to determine if this paradigm shift eased their concerns about raising a Deaf child.

The epistemology for this study was that of a Deaf epistemology with a transformative perspective. A Deaf epistemology relies on personal experiences and testimonies to document knowledge, which is broken down into three aspects; belief, truth, and justification (Holcomb, 2010). A transformative paradigm (Mertens 2003; Harris, Holmes, \& Mertens, 2009) is a system of beliefs that includes members of a minority culturally that focuses on increased social justice.

This study was part of a larger study that focused on both families and their experiences with raising a Deaf child as well as the perceptions of Deaf Mentors. Here, only the family data is discussed. The study used a qualitative method to bring to life these experiences, in contrast to the quantitative studies discussed above.

\section{Positionality}

I (Hamilton) am currently involved with early intervention as an independent consultant. I have worked with EHDI on one of their national committees. I worked with NCHAM and developed guidelines on how to establish a Deaf Mentor program in one's home state. Moreover, I am an educator that works with Deaf children and infants.

In additional to the influence of my professional experiences, my personal background and upbringing drives my interest in this project. I grew up as a Deaf person in a hearing family. I live with that experience even today. Additionally, I have two Deaf daughters. I also am an active member of the Deaf community, who advocates for Deaf children. I have been immersed in a culture that emphasizes the importance of education and lifelong learning. My professional involvement and experience with Deaf education and policies around the country creates my interest in understanding these issues.

The second author (Clark) is a hearing, European American with a background in developmental psychology. She has been immersed in ASL and Deaf culture throughout her career. She has extensive experiences and knowledge 
with publishing research in the areas of cognition, Deaf culture, and literacy.

\section{Research Questions}

RQ: What do hearing families with a Deaf child report as their experiences with the Deaf Mentor Program?

RQA: What do they see as the benefits and goals of having a Deaf Mentor?

RQB: How do the families see the importance of a Deaf epistemology and Deaf CCC?

\section{Method}

The study was a qualitative one, using a grounded theory and the method of constant comparisons analysis (CCA; Fram, 2013). The systematic model of Strauss and Corbin (1990) was used to collect, review, and identify shared themes. Both theoretical and in vivo codes were identified after the translation of the interviews. Then, there was discussion of the data among the authors, and a validity check from the peer reviewer, leading to the open coding. The second step in this process was to reduce the open codes into summary axial codes, and finally to identify the overarching component or core category. This information will be woven into a theory of how to maximize early intervention with the use of a Deaf Mentor.

Procedure. IRB approval was obtained from the university prior to beginning the study. In an attempt to get more diversity among the participants, a brief survey was sent to each state Deaf Mentor Coordinator, whose states were identified as having the Deaf Mentor Program and utilizing the SKI-HI curriculum. A post was placed on Facebook which spread the information to try to obtain a more diverse pool of participants for this qualitative study. Interested families contacted the first author and were sent the screening questionnaire to obtain the sample. Families who qualified for the sample were interviewed via video conferencing software. Given that the first author is Deaf and conducted all interviews, ASL interpreters joined Zoom for interviews with two of the families. The third family knew ASL and did not require the use of an interpreter. All interviews were video recorded for later translation into English.

Participants. Ten hearing parents completed the screening questionnaire, which included nine questions that asked for parent and child characteristics. These questions regarding parents included the following; parental age category, gender, race/ethnicity, highest level of education completed for each parent, current employment status, income in the past year, how many Deaf children were in the family, the number of Deaf relatives, and their comfort with using sign language. The information about their child included; birth date, race/ethnicity, a question that asked if the child was full term, the age when the child was identified as Deaf, whether the child have any additional disabilities, and the date they started with the Deaf Mentor Program.

Participating Families. Family participants who had a Deaf Mentor were selected after their completion of the screening questionnaire, resulting in a sam- 
ple of three families. Each of the three families were contacted three times. The first contact was to develop a relationship with the family and lasted between 30 and 40 minutes. The second contact was the first interview and included the semi-structured questions to elicit the family's view of the impact of having a Deaf Mentor. Each of the first interviews lasted between 45 minutes to one hour. The final contact with each family was to conduct member checks with them; for two of the families they were asked to expand on their original interview in terms of how they used their Deaf Mentor to become integrated into the Deaf community; these follow-up interviews lasted between 15 to 25 minutes. Saturation of the family interviews was reached when no additional information was found in the third contact.

The three families were selected to maximize the SES diversity of the sample. Here are the characteristics of each family. One family learned ASL, but at the time of the interview used spoken language in the home. One family was bilingual, using ASL and spoken English. The final family reported ASL as their child's primary language. However, all families preferred spoken English at home. Moreover, their level of confidence using sign language varied; one family identified as not comfortable, the second family said they were somewhat comfortable, and the third family was confident in their ASL skills. All of the interviewed families were European American with one having no college degree, one had some college, and the last one had a college degree. Their incomes also varied, ranging from $\$ 35,001$ to $\$ 65,000$ or more.

There were three Deaf female children and one Deaf male child. All of the children were between three to seven years of age. The children were identified as Deaf at varying ages. Moreover, the children had different types of school placement, one child was in general education, another child was in a Deaf/HH program, and the third child was in a Deaf school.

\section{Results}

\section{Core Category}

After looking at the open and axial codes, the core code, Keys to Success for Deaf/HH Children, captured the parents' experience with their Deaf Mentor.

Findings showed that the Deaf Mentor Program provided inclusive services, which addressed all of the family's concerns about how to bring up a Deaf child. Using the services provided by the Deaf Mentor allowed the families to move forward with their life, knowing that their Deaf child would have positive outcomes. Now rather than being concerned that their Deaf child would be limited in life, families had high expectations for their child. The families connected to the Deaf community for support and role models. They gained confidence about their child being Deaf and only different, not disabled. They not only learned how to raise a Deaf child but learned how to prepare them to navigate through the hearing community. Now the families have adopted I. King Jordan's belief that Deaf people can do anything, but hear (King, 2017). This belief was sup- 
ported by the Axial Codes reported in the next section.

\section{Axial Codes}

After identifying the five open codes, two axial codes organized the open codes and were labeled Acquiring Deaf Practices and LRE-Language Rich Environment (See Figure 1).

Axial Code One: Acquiring Deaf Practices. This code includes three open codes of Different not Disabled, Learning Indigenous Practices, and Resources for Child Success. Acquiring Deaf Practices includes both a Deaf perspective and a Deaf epistemology, where families were able to obtain direct knowledge about how their child could live a successful life and where to get resources. Families stated that they preferred to learn from a Deaf person who is a member of the Deaf community, as they felt it was critical to understand a Deaf perspective. The families learned about being Deaf, including the rich history of the culture, history, and language. These participants believed that this information could not be learned from hearing professionals, no matter how hard they tried to provide similar or different resources. Not having the lived experience of

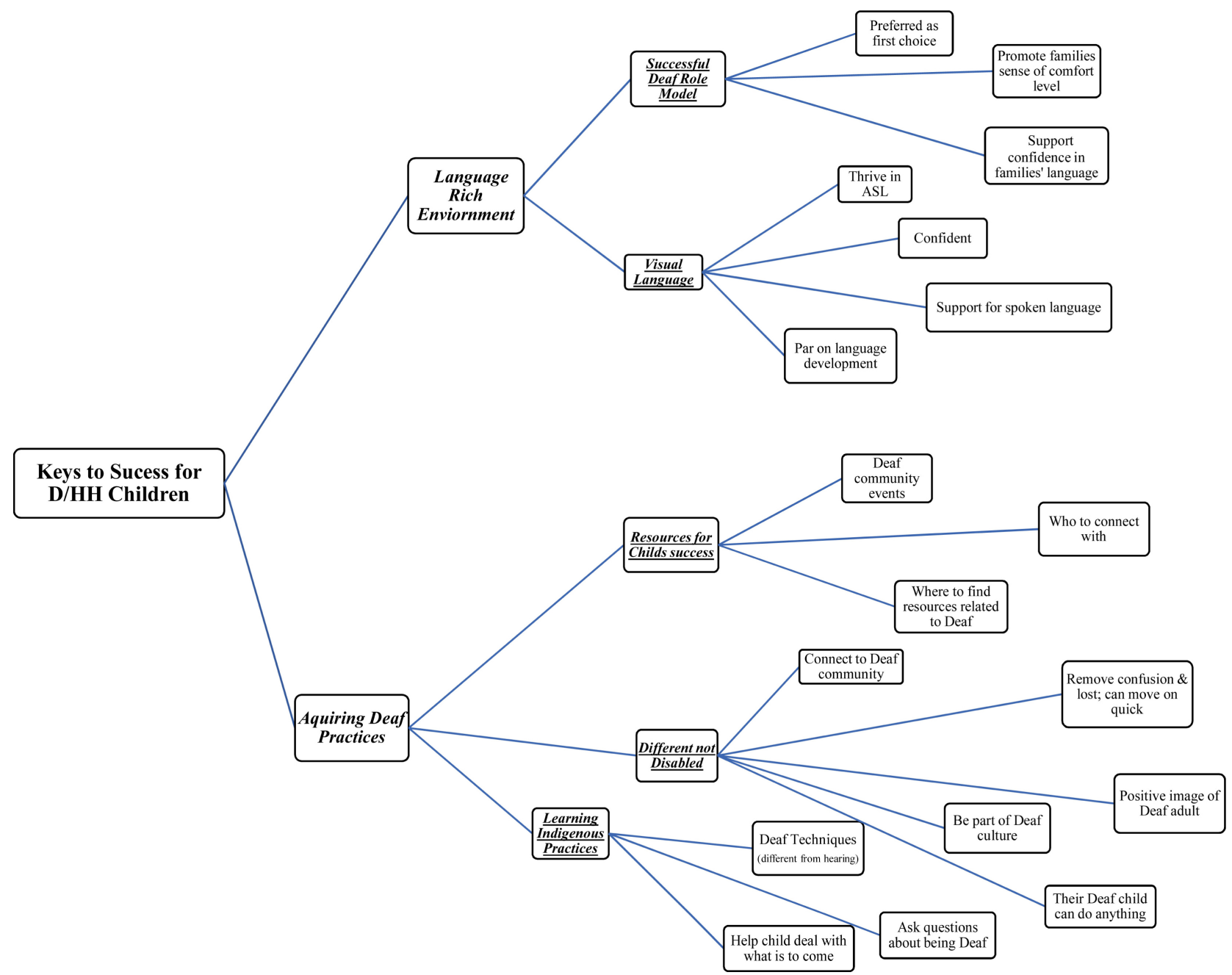

Figure 1. Components making up the Keys to Success for DHH Children. 
being Deaf, these hearing professionals could not help the families gain an emic perspective about a Deaf life. As family B said, "Before having a Deaf Mentor, I was lost, and I did not know what to do. The Deaf Mentor helps us connect with the Deaf community and understand being Deaf." These Deaf practices provided strategies for these families that have been learned and passed down within the Deaf community; they permit Deaf individuals to succeed in a hearing world.

Axial Code Two; LRE-Language Rich Environment. This code includes the open codes of Visual Language and Successful Deaf Role Models. The Deaf definition of LRE, i.e., language rich environment, captured what these families felt was vital to support the development of their Deaf child. Deaf Mentors approached the child and family as a complete unit, that could function in an adaptive and effective manner. They provided support for language development, which permitted the family to understand how a Deaf child approaches language learning. Access to a visual language and a successful Deaf role model provided the key to providing a language rich environment.

These Deaf Mentors demonstrated how a language rich environment does not happen only in the academic environment, rather it is necessary for everything in life. Language is important at home, the doctor's appointment, and even when ordering food. The families understood that language exposure is critical for the Deaf child's language development. Moreover, the families expressed that learning ASL with their Deaf Mentor increased their confidence in using ASL on a daily basis. This LRE immediately impacted their child and they noticed rapid improvement in their child's language development. As their own confidence with using ASL increased they saw corresponding improvement in their child's language. Family A commented:

I have the opportunity to practice my ASL with the Deaf Mentor and it is important for my child to see adult-to-adult conversation in ASL. It has helped me to understand significant differences between the two languages, which allows us to build a strong foundation in both languages. ASL supports her ability to thrive in her spoken language. My Deaf Mentor helped my child become confident in both of her languages.

These codes were drawn from the Open codes, which are presented below.

\section{Open Codes}

Open coding identified five different categories. for the families' overall model There were five open codes are Different not Disabled, Learning Indigenous Practices, Resources for Child Success, Visual Language, and Successful Deaf Role Model. The codes were found across all the interviews with the families. In this section, we identify the themes within each of the five open codes. Next the components under Different not Disabled are discussed.

Different not Disabled. The first open code that was identified was that families expressed the idea that their children were different, but not disabled. This idea became clear to these hearing parents as they worked with the Deaf Mentor and gained an understanding of what it is like to be Deaf from a successful Deaf 
adult. The families mentioned that the Deaf Mentor Program assured them that their child could grow up to become a productive adult with degrees in higher education and contribute to society as a successfully employed person. Family B said, "my Deaf Mentor has given me confidence that my child can do anything." One of the interview questions asked, "What about your aspiration for your Deaf child? Did your aspiration change after you receive Deaf Mentor?” The family A replied:

Yes, when my daughter was born, we did not know what to expect. With a

Deaf Mentor who has college and graduate degrees, now we became more aware that this kind of stuff is possible for a Deaf person. Definitely, our Deaf Mentor is an inspiration.

All of the families said the Deaf Mentor provided a positive image of a Deaf person, with a belief that they can do anything. The families gained knowledge of the struggle that a Deaf person can face, but also a better understanding of how to overcome obstacles. Family C said that the perspective of a Deaf person shifted them into having a positive outlook:

I don't know what my expectations were before I met the Deaf Mentor, but when I met a Deaf adult, I see that they are fine and they can have a good quality of life. I met different kind of Deaf adults, I felt good about my son and what it can be like for him when he grows up. When I was told that he was Deaf and I was sad, but I did not cry or grieve because I know that Deaf people will be fine, just like hearing people. I knew that there would be struggles in their life, but that was it.

The families expressed that, "being Deaf and identifying as a Deaf person was critical for them to become aware of possibilities and that this information can only come from a Deaf person." This open code summed up the fact the families feel this experience is the best opportunity to be able to connect to the Deaf community. They noted that a Deaf Mentor as a Deaf person has Deaf cultural capital providing these hearing families their gateway to what is being called "an invisible gem community." This relationship allowed their family to feel like they are part of Deaf culture. Family C stated, "I feel good about being able to be connecting with the Deaf community with a Deaf Mentor now. Also, I learned about many successful Deaf adults through my Deaf Mentor. I did not feel that way before having a Deaf Mentor." Family A said, "We moved from state to state and it is a challenge to find the Deaf community and without a Deaf Mentor, we would not be able to find the community." These mentors provided a solid connection, which opened many more opportunities of understanding that Deaf adults can do anything.

It is important to note that all families had many services, including parent advisors, Hands and Voices, parent to parent groups, early interventionists, and services from medical professionals. Regardless, all families reported that their confusion and anxiety for their Deaf child did not cease until they met a Deaf 
person from the Deaf Mentor Program. Through this process, they felt that they were able to remove the confusion and move on quicker with their customary life. Next, we present the second open code.

Learning Indigenous Practices. The second open code focused on learning about Deaf CCC. This code had three components identified as the families expressed the importance of being able to ask a Deaf person questions and get direct answers, which they felt was a critical part of their journey. Family B said; "I want someone who is like my son to be able to answer questions about what it is like to be Deaf." This comment reflects the importance of Deaf CCC and a Deaf epistemology, which recognizes the support system available from the Deaf community. Family A reported; "We want to be part of Deaf culture and with a Deaf Mentor we were able to connect with the Deaf community as we moved around." Family A in their moves around the country noted that the Deaf community is well connected, which ensures the support given by Deaf people can continued in other cities or states. Additionally, these Deaf professionals were able to advise families about states where the early intervention system was not necessarily always effective. Family B commented, "I want my child to see Deaf adults, I had never seen a Deaf adult before I had a Deaf child.” This situation is common where hearing people are unaware of others who are Deaf, as they are an invisible minority.

Deaf indigenous practices were mentioned throughout the interviews. These families felt that there was no way for hearing people to understand things that Deaf people would know. For instance, flashing a light to get child's attention or how to hold a book so that the child could see the book and their parents at the same time when reading a story. These parents become sensitive and aware that their child needed to "oversee" conversations rather than "overhear" them. The mother in Family B commented:

When I talk with my Deaf Mentor, we would have the conversation in ASL and my child would pay attention to our conversation. But when I had the parent advisor, we did not sign and I realized how much information my child missed. I became aware and realized that no matter how much my child can hear, my child will not always have access to sound and will be missing something. In an ASL conversation my child had complete access to language and that was important to me.

The families felt that through their Deaf Mentor they gained an understand of Deaf communication capital that made their life easier. These practices matched the visual learning strategies of the Deaf child, which are different from the learning styles of hearing children.

The families noticed that their Deaf child become enthusiastic when the Deaf Mentor arrived. These Deaf Mentors took the family places with their child to show them how a Deaf person responded when they were out in public; for example, going to a bank or ordering food at a restaurant. The families stated that these interactions helped their child understand how to "be" a Deaf person by 
providing them navigational capital. It also gave the family a glimpse of what to expect in society as a Deaf person, but most importantly these parents noted that their child understood that they were not alone and the only Deaf person in the world. The next open code was resources for child success.

Resources for Child Success. Parents discussed how the Deaf Mentor helped the families learn about the resources that would benefit both their Deaf child and their whole family. The families commented that with other early intervention personnel such as, Hands and Voices, parent to parent groups, Guide by Your Side, parent advisors, or medical professionals, they felt overwhelmed as they gave volumes of information all at once, without helping the family apply the information. Families reported that frequently the resources provided by these other professionals were not necessarily reliable or useful, leaving them feeling frustrated and not knowing what to do with the information. In contrast, with the Deaf Mentor they found themselves using the resources and having a better understanding of which resources were useful for their child. Additionally, they had a better understanding of how to connect with resources when it came to the needs of their child. These Deaf Mentors provided connections with the Deaf community and helped the family understand how to interact with the education system. The next open code is that of the benefit of visual language.

Visual Language. Families emphasized how the Deaf Mentor allowed ASL to develop, both for themselves and their child. The families felt that with the Deaf Mentor they were more confident about their ASL skills and their ability to communicate with their child. The families expressed that they strongly believed ASL allowed their child's language development to follow typical milestones. Two families, one where the child is now using mostly spoken language and another with two Deaf children who are bimodal bilinguals (i.e., using both ASL and spoken English), both believed that it was ASL that promoted their children's spoken language. None of these children had any spoken language until after they learned ASL. At that point, these children's spoken language emerged.

In terms of language. Family C commented, (My child's) "spoken language is on par with their hearing peers, but not their ASL because there are no other Deaf peers in the classroom to provide ASL stimulation." Family A stated,

Both of my children are on par with their language development. We use both languages, ASL and spoken language, and I believe that my children acquired spoken language due to ASL. The top benefit for my children is that they learned language and how to communicate. Learning ASL is stressful but is just the same as if I was learning another language.

Family B noted, "my child is comfortable acquiring language and having conversations (using full language) with the Deaf Mentor, but not with other early intervention providers." These comments show the impact of community capital in the lives of these families. It allowed their children to take advantage of a visual language, which then led to their ability to communicate using spoken lan- 
guage. It appears that the visual language established the necessary framework for language learning and then the natural language abilities of children emerged and began to follow typical language milestones. The use of visual language was due to having a successful Deaf role model, which is discussed next.

Successful Deaf Role Model. The final open code focused on interacting with successful Deaf adults. The families and their child seem to be more comfortable with a Deaf Mentor because they felt they were part of an inclusive support system. Family A said:

My husband and I wanted to give our children skills so they would have access to both worlds of spoken language and ASL. Our older daughter now prefers to talk only. We wanted to ensure that they would achieve their best and we would support them. Seeing a Deaf Mentor has helped us to know what is possible for our kids.

Family B said, "learning ASL allows us to learn a new language together with the support from our Deaf Mentor." Later they stated, "I think that this turns out easier to communicate with her because she is able to express herself and has access to language all the time." This visual language allowed these families' Deaf children an understanding of the concept of language. Having ASL also increased their children's spoken language.

That being said, the families felt like having a Deaf Mentor was a rich and significant part of the early intervention program and should be required or at least to make sure the families know that this service is available. Family A commented that Deaf Mentor provided the tools to navigate the world:

My goal is for my kids to see what Deaf people can do. They can work and become successful. Deaf adults can be the role model to us as a family as well. I want to show my girls that I am working hard to keep their culture connected to our life, as that it is a very important part of our life because my girls are Deaf.

This comment shows that the families want to obtain all of the information that was available to them. One family mentioned:

I never met a Deaf person before. I do not know of any Deaf person around here. I want my son to see a Deaf adult. I want to learn from their experience and life. Hearing people's opinion is different from Deaf people's. As I was learning about hearing aids and cochlear implants, I felt like I should also learn and hear from Deaf people too.

They noted that is it probably the critical aspect of helping each hearing family support their Deaf child's life. Family C stated, "we can learn from other's expertise, but interacting with a Deaf person is extremely important." Families rated having a Deaf Mentor as the most important part of their early intervention experience. Now after discussing these five codes, we present a rationale and theory for the inclusion of Deaf Mentors in early intervention. 


\section{Discussion}

The core category, Keys to Success for Deaf Children, integrates Deaf CCC (Listman et al., 2011) and a Deaf epistemology (Hauser et al., 2010; Holcomb, 2010) leading to the learning of strategies that help these families and their Deaf child navigate both the Deaf and hearing worlds. Families eagerly accepted this indigenous knowledge and integrated the Deaf communities CCC into their families' life. The families believed that they got important benefits from the Deaf Mentors, where their children obtained community capital including language and how to function within society as a Deaf individual. Families expressed that the Deaf Mentor's service provided a holistic approach, which covered all issues with which they were concerned, leading them to become confident that their Deaf child could be successful. All families gained aspirational capital in meeting a successful, highly educated Deaf adults, which gave them the resilience to believe that their Deaf child would be successful (Listman, et al., 2011).

Families reported developing Deaf CCC from their Deaf Mentor. They gained community capital when the Deaf Mentors served as an ASL model and then helped their child to develop language. Many families reported that learning ASL provided access to spoken language after a period of no language at all. Recall that in this study, community capital includes both linguistic and social capital (Listman et al., 2011). These kinds of capital were expressed by the families by their connection to the Deaf community through the Deaf Mentor. Families moved towards a Deaf epistemology and accepted the notion of Deaf Gain (Bauman \& Murray, 2013) in that they felt that their child enriched their families.

That being said, while all families learned ASL some families struggled more in their ASL learning. They expressed their feelings that their interactions with the Deaf Mentor and the Deaf community provided them with a more visual perspective of the world. Deaf Mentors allowed the families to learn how to provide language and to monitor their Deaf child's language development (Pittman et al., 2001).

The families' perspective shifted once they gained knowledge and an understanding of being Deaf. Initially, families did not know how to help their Deaf child become successful and frequently had been told that their child would not be able to function as a typical child. The Deaf Mentor Program changed this situation and provided aspirational and navigational capital, allowing hearing parents to see a whole world of possibilities for their Deaf child (Pittman et al., 2001). Aspirational capital is important for the families because they reported through this Deaf Mentor experience, they felt like they could focus on what they could do to move forward with their life; they reported that now they had the necessary information to allow their Deaf child to become successful (Holcomb, 2013). Families reported that their Deaf children developed aspirational capital from seeing Deaf adults who were successful. As families and their child- 
ren develop aspirational capital they became confident that they could succeed in both the Deaf and hearing worlds.

Navigational capital was provided to these families as they gained tools from the Deaf Mentors to support their Deaf child (Listman et al., 2011). Deaf children became confident with their families' support. Deaf Mentors provided advice which reassured the families and reduced their concerns about having a Deaf child, thereby empowering families. In providing this navigational capital, Deaf Mentors provided a "map" to help families through both the hearing world's system and integrated them into a Deaf world at the same time. This navigation capital allowed these families to empower their Deaf child to overcome the oppression often experienced by Deaf individuals (Benedict et al., 2009).

The families reported that when they become aware of services for their Deaf child, they felt prepared and ready to become an advocate for their Deaf child. Deaf children are aware of what they face and learned strategies that they would need to adapt their lifestyle and become successful in the hearing world (Holcomb, 2013). This understanding provided resistance capital initially given to the families to help their child avoid oppression, which is later transferred to their Deaf child. Families became convinced that their child needed to develop a Deaf identity, through community and aspirational capitals (Listman, et al., 2011). With a Deaf identity these children gained grit and learned resilience to be able to function as a Deaf person in a hearing world.

Teaching indigenous practices is how Deaf Mentors provide Deaf CCC, as they are Deaf themselves (Benedict et al., 2009). The Deaf child then was able to acquire this knowledge through the eyes of their Deaf Mentor; in addition, families become supportive of their Deaf child. Together the Deaf child and their family took the journey together towards maximizing their child's abilities and to be proud of being a Deaf individual (Holcomb, 2013).

This Deaf epistemology develops through families' experiences with the Deaf community (Hauser, et al., 2010). Parents learned through the Deaf community how Deaf people thrive in a hearing world (Holcomb, 2013). The surprising finding for these parents was that ASL allowed the development of spoken language for their Deaf children (Hassanzadeh, 2012). This message is critical to share with hearing parents, that early exposure to a visual language "jump starts" the brain (Mayberry et al., 2011; Pénicaud, et al, 2013). The idea that ASL hurts spoken language is still promoted, as shown by the new article by Geers, Mitchell, Warner-Czyr, Wang, and Eisenberg (2017). Geers et al. ignore current information from the studies supporting the result the ASL promotes spoken language. No one will debate that some Deaf children thrive without sign language, but what is indisputable is that many do not thrive and are transferred to bilingual programs after the critical period for language. Like Sugar (2016), many people are not aware of the current neuroscience research and make inaccurate statements that if spoken language is not successful it is easier to learn a sign language later in life. These myths harm Deaf children as noted by Humphries et al. (2012) and lead to what is currently referred to as language deprivation syn- 
drome (Hall, et al., 2017).

Keys to Success for Deaf Children is the integration of the best of both the Deaf and hearing worlds. With a Deaf identity, family support, language access, and Deaf CCC these families gained confidence that their child could do anything. They were proud of their child's skills and abilities and confident that they would grow up to become successful adults. The fear and expectations of limitations for their child's future were left behind as they entered a new Deaf world; they found they were invited and welcome as part of this Deaf world and relaxed into parenting a different, but not a disabled, child. Therefore, the theory they embraced with to give their differently abled child everything to created unlimited possibilities. They left behind the standard epistemology that their child was "broken" and would be severely limited in their lifetimes. They embraced a bimodal bilingual/bicultural world that was bright and hopeful. Deaf gain centered them and allowed them to continue the dreams they had for their child before hearing that their infant failed their hearing test. They re-centered and learned that "Deaf can do anything". Providing Deaf CCC righted their world, which was richer for including both the Deaf and hearing worlds.

\section{Implications}

Here Deaf Mentors eased the stress for families who had a Deaf infant. They provided aspirational capital to these hearing parents who are concerned that their child will be "mute", never achieve academically, and not become a productive member of society, which are fears often produced when medical professionals tell hearing parents that their Deaf infant has "failed" their newborn infant hearing screening (Benedict \& Stecker, 2011). Meeting and working with these successful Deaf adult role models provides the confidence that these parents need to be comfortable raising a "different" child, but one that they know can become a productive adult who goes to college and can earn graduate degrees. In addition, developing connections to the Deaf community provides these hearing parents with strategies that seem novel to them, but have a long cultural tradition within the Deaf community. Finally, these parents now feel that they have the "keys" to helping their child become a bilingual bicultural successful individual with the new knowledge they gained about Deaf CCC.

\section{Future Research and Limitations}

This study highlights the importance of providing hearing families with access to Deaf CCC and a Deaf epistemology. Given the benefits these families report as they move towards Deaf Gain (Bauman \& Murray, 2013), future research should focus on developing this understanding among those who still hold the Medical/Audiological Perspective. Focus groups between early interventionists, audiologists, and Deaf Mentors could open a dialogue that would increase the collaborations between these types of professionals.

Surveys to these professionals trained within the Medial/Audiological Perspective could highlight myths and help to debunk them. It is possible that hearing professionals have incorporated these myths and simply do not challenge or 
understand how words like "hearing impaired" impact those who are trained within these systems. Critical pedagogy could be then integrated into medical schools and Au. D. programs to encourage students to be more inclusive of language opportunities across the spectrum. At minimum, establishing a study where a successful Deaf adult was included in the UNHS team could help provide information regarding the impact of how a hearing adult adjusts to the information that their infant is Deaf (Benedict, 2013).

Another potential study could happen at EDHI conferences, where surveys could be sent out regarding the participants' epistemology. These surveys could be collated and then presented at the next year's conferences to highlight the epistemologies found among participants. This type of multi-step process could lead to future focus groups and workshops on understanding how science is not neutral.

Additional research could utilize the life script methodology developed by Berntsen and Rubin (2004) and used in the Clark and Daggett (2015) and the Wolsey et al. (2016) studies of native versus non-native signers. Parents of recently identified Deaf children could be asked to express their expectations for their Deaf infant, which could then be followed up by information about how native versus non-native Deaf adults view their own life scripts. This type of information may help parents understand that their Deaf infant is different, but not a deficit Being; rather their Deaf child is a visual Being rather than an audiological Being.

This study has limitations as do all studies. First is the small sample size, which limits the generalizability of the study. Also, this study did not include those who declined the services of the Deaf Mentor Program. Having a broader view of these various groups would be worthwhile to provide a full picture of why families accept or reject the Deaf Mentor Program. Another limitation is the study did not interview parents who are racially diverse. Even with these limitations, the new theoretical perspective provided here supports other research that shows the importance of having early access to sign language (Mayberry et al., 2011; Pénicaud et al, 2013) and providing children with a bilingual background (Freel et al., 2011; Hrastinski \& Wilbur, 2016) that includes the types of capital found in Deaf CCC.

\section{Summary}

In summary, those families who selected Deaf Mentors reported that their child was thriving as a bilingual child. Here the collaboration of Deaf adults with hearing families with a Deaf child allowed children to become successful and parents to have high expectations for these Deaf infants and toddlers. The results point to the importance of including medical professionals and Deaf Mentors into early intervention to ensure that no family is left behind and that every Deaf child is provided with a promising quality of life.

\section{Conflicts of Interest}

The authors declare no conflicts of interest regarding the publication of this paper. 


\section{References}

Bauman, H., \& Murray, J. (2013). Deaf Studies in the 21st Century: "Deaf-Gain" and the Future of Human Diversity. The Disability Studies Reader, 4, 246-262.

Benedict, B. (2013). How Early Intervention Can Make a Difference: Research and Trends. The VL2 Educational Neuroscience Presentation Series, 2. [Video Webinar] Clerc Center Presentation Series. https://www.gallaudet.edu/Documents/Clerc/Benedictwebinar.pdf

Benedict, B., Crace, J., Hossler, T., Oliva, G., Raimondo, B., Richmond, M. A. et al. (2009). Deaf Community Support for Families: The Best of Partnerships (Ch. 11). National Center for Hearing Assessment and Management e-Book: A Resource Guide for Early Hearing Detection and Intervention (EHDI). Logan, UT: National Center for Hearing Assessment and Management, Utah State University, Logan, UT.

Benedict, R., \& Stecker, E. (2011). Early Intervention: The Missing Link. ASLized! Journal of American Sign Language and Literature, 1. http://aslized.org/journal/ei

Berntsen, D., \& Rubin, D. C. (2004). Cultural Life Scripts Structure Recall from Autobiographical Memory. Memory \& Cognition, 32, 427-442. https://doi.org/10.3758/BF03195836

Butler, R., Skelton, T., \& Valentine, G. (2001). Language Barriers: Exploring the Worlds of the Deaf. Disability Studies Quarterly, 21, 42-52. https://doi.org/10.18061/dsq.v21i4.316

Cawthon, S., Johnson, P., Garberolgio, C., \& Schoffstall, S. (2016). Role Models as Facilitators of Social Capital for Deaf Individuals: A Research Synthesis. American Annals of the Deaf, 161, 115-127. https://doi.org/10.1353/aad.2016.0021

Clark, M., \& Daggett, D. (2015). Exploring the Presence of a Deaf American Cultural Life Script. Deafness \& Education International, 17, 194-203. https://doi.org/10.1179/1557069X15Y.0000000005

Corina, D., \& Singleton, J. (2009). Developmental Social Cognitive Neuroscience: Insights from Deafness. Child Development, 80, 952-967. https://doi.org/10.1111/j.1467-8624.2009.01310.x

Davidson, K., Lillo-Martin, D., \& Chen Pichler, D. (2014). Spoken English Language Development among Native Signing Children with Cochlear Implants. Journal of Deaf Studies and Deaf Education, 19, 238-250. https://doi.org/10.1093/deafed/ent045

Fram, S. M. (2013). The Constant Comparative Analysis Method Outside of Grounded Theory. The Qualitative Report, 18, 1-25. http://nsuworks.nova.edu/tqr/vol18/iss1/1

Freel, B. L., Clark, M. D., Anderson, M. L., Gilbert, G. L., Musyoka, M. M., \& Hauser, P. C. (2011). Deaf Individuals' Bilingual Abilities: American Sign Language Proficiency, Reading Skills, and Family Characteristics. Psychology, 2, 18-23. https://doi.org/10.4236/psych.2011.21003

Geers, A. E., Mitchell, C. M., Warner-Czyz, A., Wang, N., \& Eisenberg, L. S. (2017). Early Sign Language Exposure and Cochlear Implantation Benefits. Pediatrics, 140, 1-9. https://doi.org/10.1542/peds.2016-3489

Goldin-Meadow, S., \& Mayberry, R. I. (2001). How Do Profoundly Deaf Children Learn to Read? Learning Disabilities Research \& Practice, 16, 222-229. https://doi.org/10.1111/0938-8982.00022

Grosjean, F. (2008). Studying Bilinguals. Oxford, UK: Oxford University Press.

Hall, W. C., Levin, L. L., \& Anderson, M. L. (2017). Language Deprivation Syndrome: A Possible Neurodevelopmental Disorder with Sociocultural Origins. Social Psychiatry and Psychiatric Epidemiology, 52, 761-776. 
https://doi.org/10.1007/s00127-017-1351-7

Hamilton, B. (2013). How Will the Deaf Mentor Program Be Useful for Deaf and Hard of Hearing Children, Their Families, and the Professionals with Whom They Interact? Unpublished Thesis, Oregon, Portland: Department of Education, Marylhurst University.

Hamilton, B. (2017). The Deaf Mentor Program: Benefits to Families and Professionals. Lamar University-Beaumont.

Harmon, K. (2013). Growing up to become hearing: Dreams of 'Passing' in oral Deaf education. In: J. Brune, \& D. Wilson (Eds.), Disability and Passing: Blurring the Lines of Identity (pp. 167-198). Philadelphia, PA: Temple University Press.

Harris, R., Holmes, H., \& Mertens, D. (2009). Research Ethics in Sign Language Communities. Sign Language Studies, 9, 104-131. https://doi.org/10.1353/sls.0.0011

Hassanzadeh, S. (2012). Outcomes of Cochlear Implantation in Deaf Children of Deaf Parents: Comparative Study. The Journal of Laryngology \& Otology, 126, 989-994. https://doi.org/10.1017/S0022215112001909

Hauser, P. C. (2013). Deaf Scientists Need Deaf Mentors. Lisbon, Portugal: Paper Presented at the 6th International Deaf Academics and 33 Researchers Conference.

Hauser, P., O’Hearn, A., McKee, M., Steider, A., \& Thew, D. (2010). Deaf Epistemology: Deafhood and Deafness. American Annals of the Deaf, 154, 486-492. https://doi.org/10.1353/aad.0.0120

Hintermair, M. (2000). Hearing Impairment, Social Networks, and Coping: The Need for Families with Hearing-Impaired Children to Relate to Other Parents and to Hearing-Impaired Adults. American Annals of the Deaf, 14, 41-53.

https://doi.org/10.1353/aad.2012.0244

Holcomb, T. (2010). Deaf Epistemology: The Deaf Way of Knowing. American Annals of the Deaf, 154, 471-478. https://doi.org/10.1353/aad.0.0116

Holcomb, T. K. (2013). Introduction to American Deaf Culture. Oxford, NY: Oxford University Press.

Hrastinski, I., \& Wilbur, R. B. (2016). Academic Achievement of Deaf and Hard-of-Hearing Students in an ASL/English Bilingual Program. Journal of Deaf Studies and Deaf Education, 21, 156-170. https://doi.org/10.1093/deafed/env072

Humphries, T., Kushalnagar, P., Mathur, G., Napoli, D. J., Padden, C., \& Rathmann, C. (2014). Ensuring Language Acquisition for Deaf Children: What Linguists Can Do. Language, 90, 31-52. https://doi.org/10.1353/lan.2014.0036

Humphries, T., Kushalnagar, P., Mathur, G., Napoli, D. J., Padden, C., Pollard, R., \& Smith, S. (2014). What Medical Education Can Do to Ensure Robust Language Development in Deaf Children. Medical Science Educator, 24, 409-419.

https://doi.org/10.1007/s40670-014-0073-7

Humphries, T., Kushalnagar, P., Mathur, G., Napoli, D. J., Padden, C., Rathmann, C., \& Smith S. R. (2012). Language Acquisition for Deaf Children: Reducing the Harms of Zero Tolerance to the Use of Alternative Approaches. Harm Reduction Journal, 9, 16-24. https://doi.org/10.1186/1477-7517-9-16

Humphries, T., Kushalnagar, P., Mathur, G., Napoli, D. J., Padden, C., Rathmann, C., \& Smith, S. (2016). Language Choices for Deaf Infants. Clinical Pediatrics, 55, 513-517. https://doi.org/10.1177/0009922815616891

Jacobi, M. (1991). Mentoring and Undergraduate Academic Success: A Literature Review. Review of Educational Research, 61, 505-532. https://doi.org/10.3102/00346543061004505 
Johnson, R., Liddell, S., \& Erting, C. (1989). Unlocking the Curriculum. Washington DC: Gallaudet Research Institute. Working Paper 89-3.

Klaudia, K. (2013). The Benefits of Sign Language for Deaf Children with and without Cochlear Implant(s). European Scientific Journal, 4, 341-349.

Kushalnagar, P., Mathur, G., Moreland, C., Napoli, D., Osterling, W., Padden, C., \& Rathmann, C. (2010). Infants and Children with Hearing Loss Need Early Language Access. The Journal of Clinical Ethics, 21, 143-154.

Lakoff, G. (2004). Don't Think of an Elephant!: Know Your Values and Frame the Debate: The Essential Guide for Progressives. White River Junction, VT: Chelsea Green Pub. Co.

Lane, H. (2005). Ethnicity, Ethics, and the Deaf-World. Journal of Deaf Studies and Deaf Education, 10, 291-310. https://doi.org/10.1093/deafed/eni030

Leigh, I. W., Andrews, J. F., \& Harris, R. (2018). Deaf Culture: Exploring Deaf Communities in the United States. San Diego, CA: Plural Publishing.

Lieberman, A. M., Hatrak, M., \& Mayberry, R. I. (2011). The Development of Eye Gaze Control for Linguistic Input in Deaf Children. In BUCLD 35: Proceedings of the 35th Annual Boston University Conference on Language Development (pp. 391-403). Somerville, MA: Cascadilla.

Lieberman, A. M., Hatrak, M., \& Mayberry, R. I. (2014). Learning to Look for Language: Development of Joint Attention in Young Deaf Children. Language Learning and Development: The Official Journal of the Society for Language Development, 10, 19-35. https://doi.org/10.1080/15475441.2012.760381

Listman, J., Rogers, K. D., \& Hauser, P. C. (2011). Community Cultural Wealth and Deaf Adolescents' Resilience. In D. H. Zand, \& K. J. Pierce (Eds.), Resilience in Deaf Children: Adaptation through Emerging Adulthood (pp. 279-297). Berlin, Germany: Springer Science. https://doi.org/10.1007/978-1-4419-7796-0 11

Marschark, M. (2001). Language Development in Children Who Are Deaf: A Research Synthesis (EC 308 491). Washington DC: U.S. Government Printing Office.

Mauldin, L. (2016). Made to Hear: Cochlear Implants and Raising Deaf Children. Minneapolis, MN: University of Minnesota Press. https://doi.org/10.5749/minnesota/9780816697243.001.0001

Mayberry, R. I. (2002). Cognitive Development of Deaf Children: The Interface of Language and Perception in Neuropsychology. In S. J. Segaolwitz, \& I. Rapin (Eds.), Handbook of Neuropsychology (Vol. 8, pp. 71-107). Amsterdam, Netherlands: Elsevier.

Mayberry, R. I., \& Lock, E. (2003). Age Constraints on First versus Second Language Acquisition: Evidence for Linguistic Plasticity and Epigenesis. Brain and Language, 87, 369-384. https://doi.org/10.1016/S0093-934X(03)00137-8

Mayberry, R. I., Chen, J. K., Witcher, P., \& Klein, D. (2011). Age of Acquisition Effects on the Functional Organization of Language in the Adult Brain. Brain and Language, 119, 16-29. https://doi.org/10.1016/j.bandl.2011.05.007

Mertens, D. M. (2003). Mixed Methods and the Politics of Human Research: The Transformative-Emancipatory Perspective. In A. Tashakkori, \& C. Teddlie (Eds.), Handbook of Mixed Methods in Social and Behavioral Research (pp. 135-164). Thousand Oaks, CA: Sage.

Minnesota Department of Health Newborn \& Child Follow-Up Unit (2015). Secondary Data Requested by Wilder Research for the Needs Assessment for Families with Young Children (Age 0-6) Who Are Deaf and Hard of Hearing. Unpublished Report. 
Mitchiner, J. (2015). Deaf Parents of Cochlear-Implanted Children: Beliefs on Bimodal Bilingualism. Journal of Deaf Studies and Deaf Education, 20, 51-66. https://doi.org/10.1093/deafed/enu028

National Center for Hearing Assessment and Management Utah State University (NCHAM) (2020) http://www.infanthearing.org/

Nussbaun, D. B., Scott, S., \& Simms, L. E. (2004). The "Why" and "How" of an ASL/English Bimodal Bilingual Program. Odsessy: New Directions in Deaf Education, 13, 14-19.

Padden, C., \& Humphries, T. (1989). Deaf in America: Voices from a Culture. Ear and Hearing, 10, 139. https://doi.org/10.1097/00003446-198904000-00022

Pénicaud, S., Klein, D., Zatorre, R., Chen, J, Witcher, P., Hyde, K., \& Mayberry, R. (2013). Structural Brain Changes Linked to Delayed First Language Acquisition in Congenitally Deaf Individuals. NeuroImage, 66, 42-49. https://doi.org/10.1016/j.neuroimage.2012.09.076

Petitto, L., \& Holowka, S. (2002). Evaluating Attributions of Delay and Confusion in Young Bilinguals: Special Insights from Infants Acquiring a Signed and a Spoken Language. Sign Language Studies, 3, 4-33. https://doi.org/10.1353/sls.2002.0025

Pittman, P., SKI-HI Institute (Utah State University), \& HOPE, Inc. (2001). The Deaf Mentor Curriculum: A Resource Manual for Home-Based, Bilingual-Bicultural Programming for Young Children Who Are Deaf. Logan, UT: SKI-HI Institute, Utah State University.

Rhodes, J., \& DuBois, D. (2008). Mentoring Relationships and Programs for Youth. Current Directions in Psychological Science, 17, 254-258. https://doi.org/10.1111/j.1467-8721.2008.00585.x

Rhodes, J., Grossman, J., \& Resch, N. (2000). Agents of Change: Pathways through Which Mentoring Relationships Influence Adolescents' Academic Adjustment. Child Development, 71, 1662-1671. https://doi.org/10.1111/1467-8624.00256

Rhodes, J., Spencer, R., Keller, T., Liang, B., \& Noam, G. (2006). A Model for the Influence of Mentoring Relationships on Youth Development. Journal of Community Psychology, 34, 691-707. https://doi.org/10.1002/jcop.20124

Rinaldi, P., \& Caselli, M. C. (2014). Language Development in a Bimodal Bilingual Child with Cochlear Implant: A Longitudinal Study. Bilingualism: Language and Cognition, 17, 798-809. https://doi.org/10.1017/S1366728913000849

Rogers, K., \& Young, A. (2011). Being a Deaf Role Model: Deaf People's Experiences of Working with Families and Deaf Young People. Deafness \& Education International, 13, 2-16. https://doi.org/10.1179/1557069X10Y.0000000004

Simms, L., Baker, S., \& Clark, M. (2013). The Standardized Visual Communication and Sign Language Checklist for Signing Children. Sign Language Studies, 14, 101-123. https://doi.org/10.1353/sls.2013.0029

Singleton, J. L., \& Tittle, M. D. (2000). Deaf Parents and Their Hearing Children. Journal of Deaf Studies and Deaf Education, 5, 221-236. https://doi.org/10.1093/deafed/5.3.221

Solomon, A. (2012). Far from the Tree: Parents, Children and the Search for Identity. New York: Scribner.

Strauss, A., \& Corbin, J. (1990). Basics of Qualitative Research: Grounded Theory Procedures and Techniques. Newbury Park, CA: Sage Publications.

Sugar, M. (2016). AG Bell: Dispelling Myths about Deafness-Baltimore Post. http://baltimorepostexaminer.com

Swanwick, R., \& Watson, L. (2005). Literacy in the Homes of Young Deaf Children: 
Common and Distinct Features of Spoken Language and Sign Bilingual Environments. Journal of Early Childhood Literacy, 5, 53-78. https://doi.org/10.1177/1468798405050594

Vasquez, O., Pease-Alvarez, L., \& Shannon, S. (1994). Pushing Boundaries: Language and Culture in a Mexicano Community. Cambridge, MA: Cambridge University Press. https://doi.org/10.1017/CBO9780511663970

Watkins, S., Pittman, P., \& Walden, B. (1998). The Deaf Mentor Experimental Project for Young Children Who Are Deaf and Their Families. American Annals of the Deaf, 143, 29-34. https://doi.org/10.1353/aad.2012.0098

Wolsey, J. A., Clark, M. D., van der Mark, L., \& Suggs, C. (2016). Life Scripts and Life Stories of Oral Deaf Individuals. Journal of Developmental and Physical Disabilities, 29, 1-27. https://doi.org/10.1007/s10882-016-9490-4

Yosso, T. J. (2005). Whose Culture Has Capital? A Critical Race Theory Discussion of Community Cultural Wealth. Race Ethnicity and Education, 8, 69-91. https://doi.org/10.1080/1361332052000341006

Zhelev, Z., Hyde, C., Fitzgerald, J. E., Ukoumunne, O., Briscoe, S., Chisnell, J., \& Grigore, B. (2015). Tests for Screening for Hearing Loss in Children about to Start School (Protocol). Cochrane Database of Systematic Reviews, 11, CD011951.

https://doi.org/10.1002/14651858.CD011951 